\title{
A Study of Microsegregation in Al-Cu Using a Novel Single- Pan Scanning Calorimeter
}

\author{
H.B. DONG, M.R.M. SHIN, E.C. KURUM, H. CAMA, and J.D. HUNT
}

A single-pan scanning calorimeter has been developed that eliminates the smearing of latent heat that occurs in a conventional two-pan heat-flux differential scanning calorimeter (DSC). In the new calorimeter, accurate enthalpy/temperature data was obtained in pure Al without smearing, and excellent sensitivity to new phases was obtained in a multicomponent Al alloy (LM25). The calorimeter has been used to investigate microsegregation in an Al-4.45 wt pct $\mathrm{Cu}$ alloy. The enthalpy/temperature data fell between that calculated, assuming no mixing in the solid (Scheil) and complete mixing in the solid (equilibrium solidification). The amount of segregation agreed well with that calculated using a diffusion-based model of microsegregation. The difficulty of getting the fraction solid from the enthalpy data is discussed, and it is concluded that it is not possible to do so without using a microsegregation model. In addition, it is concluded that it is wrong to assume that the enthalpy of an alloy can be given by a specific heat term and a constant latent heat term that depend on fraction liquid as is assumed in most casting models.

\section{INTRODUCTION}

TRADITIONALLY a two-pan heat-flux differential scanning calorimeter (DSC) is used to measure thermal properties as a function of temperature. ${ }^{[1-5]}$ Problems arise when latent heat is evolved. The heat appears to be evolving over a range of temperatures. ${ }^{[6,7,8]}$ In this article, the reason for this smearing of the latent heat is briefly discussed, and a novel single-pan calorimeter is described that eliminates smearing. Experiments are reported that investigate the reproducibility and sensitivity in the new calorimeter.

The new calorimeter has been used to investigate microsegregation in an $\mathrm{Al}-\mathrm{Cu}$ alloy, and the results are compared with Alloy/M, ${ }^{[9]}$ a microsegregation model that is linked with the thermodynamic database package MTDATA. ${ }^{[10]}$

\section{PROBLEMS WITH A TWO-PAN HEAT- FLUX DSC}

A schematic diagram of a two-pan heat-flux DSC is shown in Figure 1. In use, the temperature of the surroundings is scanned at a constant rate, and the temperature difference between the reference and the sample thermocouples is used to calculate the difference in heat capacity between the reference and the sample. Problems arise when latent heat is evolved or absorbed. These are illustrated in Figure 2. The figure shows the temperature of the surroundings, $T_{F}$, the temperature of the sample pan thermocouple, $T_{S P}$, the temperature of the reference pan thermocouple, $T_{R P}$, and the temperature of the sample, $T_{S}$, plotted against time. When a pure metal sample melts, its temperature stays constant,

H.B. DONG, Postdoctor, M.R.M. SHIN and E.C. KURUM, Doctoral Students, and J.D. HUNT, Professor, are with the Department of Materials University of Oxford, Oxford, United Kingdom OX1 3PH. Contact e-mail: John.Hunt@materials.ox.ac.uk H. CAMA, Research Scientist, is with Alcan International Limited, Banbury Oxon, United Kingdom OX16 2SP.

This article is based on a presentation given in the symposium "Fundamentals of Solidification," which occurred at the TMS Fall meeting in Indianapolis, Indiana, November 4-8, 2001, under the auspices of the TMS Solidification Committee. and the heat flux increases. The increased heat flux leads to a larger temperature difference between the sample and the external sample thermocouple. After the sample has melted, the sample temperature returns to the steady state value. It is usual to assume that the difference in heat capacity between the sample and reference thermocouples is proportional to the temperature difference between the sample and reference. The temperature difference is plotted as a function of the sample thermocouple temperature in Figure 2(b). It is clear from this diagram that the latent heat appears to be evolving over a range of temperatures. Although corrections can be made, ${ }^{[7]}$ they are difficult to carry out because the various heat transfer coefficients are not completely reproducible. To reduce this smearing of latent heat, calorimeter manufacturers usually recommend using very small samples ( $\sim 1 \mathrm{mg}$ ); but even with this small size, the latent heat typically appears to be smeared over about $3 \mathrm{~K}$ in a pure material. Further, the very small sample size leads to a lack of resolution and sensitivity. These criticisms apply equally well to differential thermal analysis (DTA). The DTA is very similar to a heat-flux DSC, ${ }^{[11]}$ but the emphasis is put on the detection of phase transitions rather than on the measurement of enthalpy.

\section{SINGLE-PAN CALORIMETER}

A single-pan calorimeter has been developed that eliminates smearing. The essential feature of the new calorimeter is that the sample is in a uniform temperature enclosure, and it has the largest possible thermal resistance between the sample and its surroundings. A schematic diagram of the apparatus is shown in Figure 3. To ensure a uniform temperature enclosure, the outer crucible is thermally isolated from the furnace, is thick walled, and made of a material with a high conductivity. The inner crucible is thermally isolated from the outer crucible to ensure the maximum temperature difference between the two crucibles. The sample is made large enough so that the sample thermocouple can be placed inside the specimen. In principle, there is no disadvantage in using large samples, provided significant 


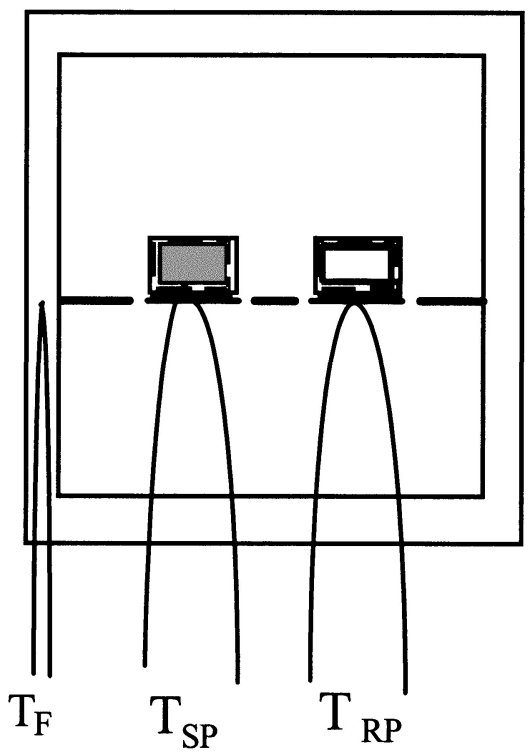

Fig. 1-Schematic view of heat-flux DSC.

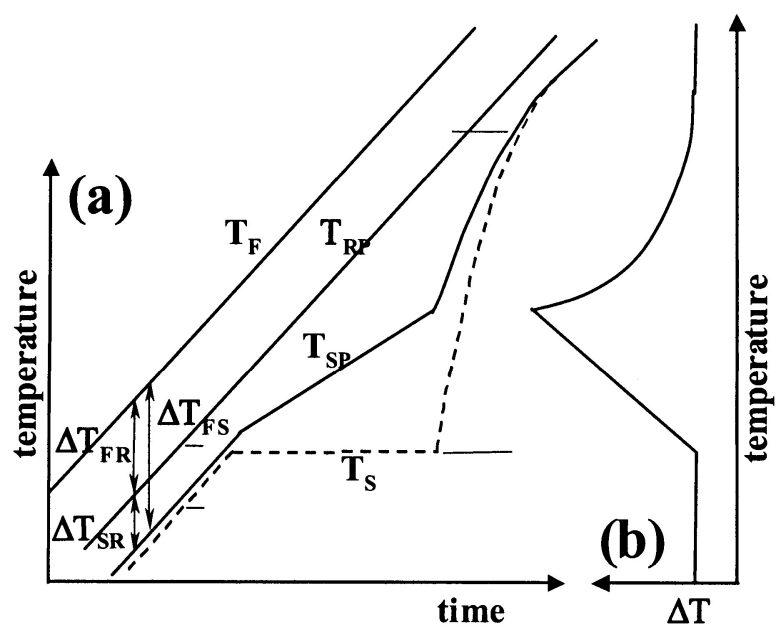

Fig. 2-(a) The temperature of the furnace $\left(T_{F}\right)$, reference pan thermocouple $\left(T_{R P}\right)$, sample pan thermocouple $\left(T_{S P}\right)$, and sample $\left(T_{S}\right)$ for melting a pure metal in a conventional two-pan DSC. (b) The temperature difference between the reference pan and sample pan as a function of a temperature is shown in (a).

temperature differences do not arise in the sample. Thermocouples $(0.5-\mathrm{mm}$ outer diameter) are placed in the walls of the inner and outer crucibles. An additional thermocouple sheathed in alumina is placed in the center of the sample. Typically, the sample is a machined cylinder $10 \mathrm{~mm}$ in diameter and 10-mm high. A 7-mm deep hole is drilled in the center of the sample for the thermocouple. The dimensions of the sample used are shown in Figure 3, and the rest of the figure is drawn approximately to scale. Typically for pure $\mathrm{Al}$, the samples were about $2.7 \mathrm{~g}$.

The calorimeter can be operated in the normal DSC manner by changing the outer crucible temperature at a constant programmed rate. Because the specimens are much larger than for a conventional heat-flux DSC, the calorimeter can be operated in a constant heat-flux mode, as was proposed by Smith in $1940 .{ }^{[13]}$ In this mode, the temperature difference between the inner and outer crucibles is kept constant by

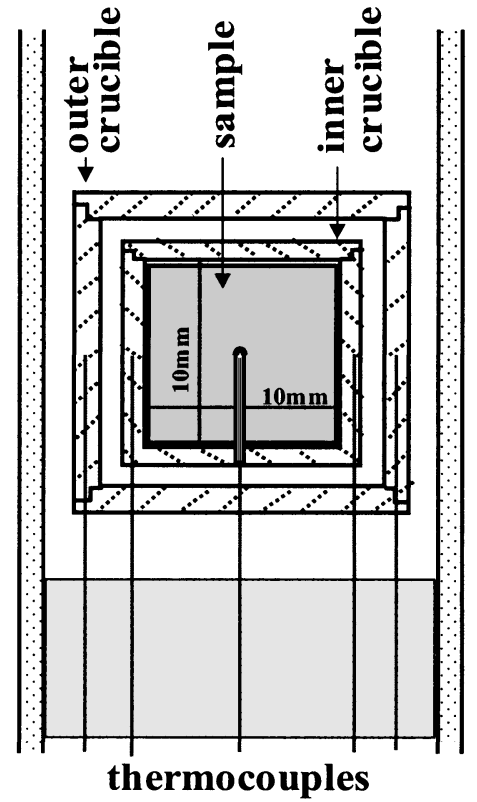

Fig. 3-Schematic diagram of the single-pan scanning calorimeter.

feeding the difference in temperature to the temperature controller rather than a temperature. This means that the temperature rises less rapidly when latent heat is absorbed or evolved.

\section{ENTHALPY CALCULATION}

Because of the simplicity of the single-pan calorimeter, equations are easily derived to relate temperature changes to enthalpy changes. As in a conventional DSC, a run is carried out with an empty pan, the empty pan + calibrant, and the empty pan + sample. The temperature differences are first corrected with a zero line adjustment. These are measured during an isothermal anneal ${ }^{[8,12]}$ at a number of different temperatures.

As the calorimeter is heated in the time interval, $d t$, the temperature of the empty inner crucible rises by $d T_{E}$, the calibrant + empty rises by $d T_{C}$, and the sample + empty rises by $d T_{S}$. The corresponding temperature differences between the inner and outer crucibles for the three cases are $\Delta T_{D E}, \Delta T_{D C}$, and $\Delta T_{D S}$. Let $C_{C}$ be the change in heat content per degree (i.e., heat capacity times mass) of the calibrant; this must be known as a function of temperature. Similarly, $C_{E}$ and $C_{S}$ are those of the empty crucible and sample. It should be noted that $C_{S}$ contains any latent heat and is, thus, an effective heat capacity. The heat transfer coefficient between the inner and outer crucible, $a$, is a function of temperature.

For the empty crucible, $a \Delta T_{D E} d t=C_{E} d T_{E}$

For the calibrant + empty, $a \Delta T_{D C} d t=\left(C_{C}+C_{E}\right) d T_{C}$

For the sample + empty, $a \Delta T_{D S} d t=\left(C_{S}+C_{E}\right) d T_{S}$

Eliminating $a$ and $C_{E}$ gives a general expression for the rise in enthalpy of the sample, $d H_{S}$

$$
C_{C}\left(\frac{\Delta T_{D S}-\frac{\Delta T_{D E}}{d T_{E}} d T_{S}}{\frac{\Delta T_{D C}}{d T_{C}}-\frac{\Delta T_{D E}}{d T_{E}}}\right)=C_{S} d T_{S}=d H_{S}
$$




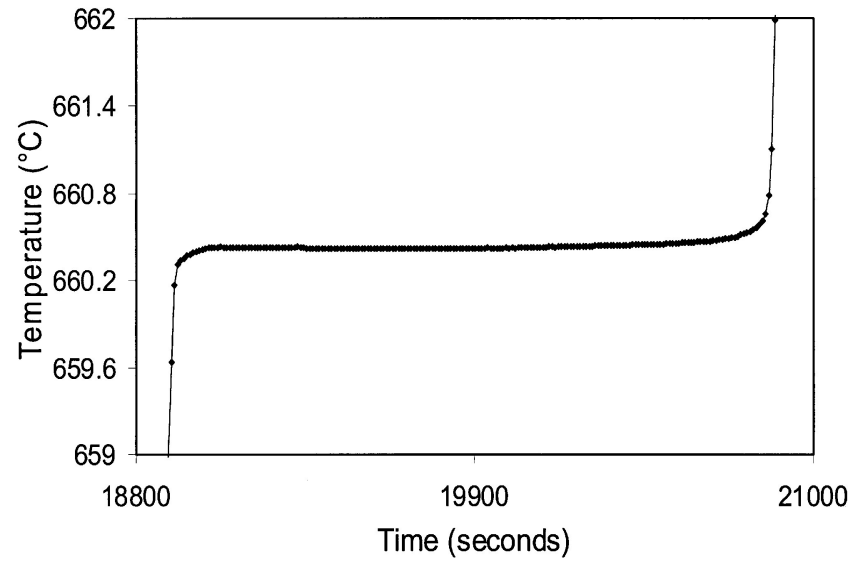

Fig. 4-Measured sample temperature $v s$ time for the melting of pure Al.

The equation is valid as $C_{S} \rightarrow \infty$ and $d T_{S} \rightarrow 0$ and can, thus, handle the latent heat of a pure material. The ratios $\Delta T_{D E} / d T_{E}$ and $\Delta T_{D C} / d T_{C}$ are evaluated from the empty and calibrant + empty run at the relevant temperature using the same time interval. Because of the stability of the system, these only need to be measured once. The meaning of these terms is best visualized by noting that the inverse of $\Delta T_{D E}$ / $d T_{E}$ divided by the time interval is $\frac{d T_{E}}{d t} \frac{1}{\Delta T_{D E}}$ and is the rate of rise in temperature of the empty pan divided by the difference in temperature between the inner and outer crucible. The general Eq. [1] is valid for any mode of operation and that includes constant rate of temperature rise or constant heat flux. The equation and the use of a central thermocouple automatically handle the desmearing process.

\section{RESULTS: SMEARING, REPRODUCIBILITY, AND SENSITIVITY}

\section{A. Apparent Melting Range for Pure Al}

Figure 4 shows the sample temperature plotted against time for pure $\mathrm{Al}$. In these experiments the temperature difference between the inner and outer crucible was set to be $6 \mathrm{~K}$ for heating and $-6 \mathrm{~K}$ for cooling. The inner crucible was alumina, and the outer crucible was boron nitride; this gave a heating rate in the absence of latent heat evolution of about $3.4 \mathrm{~K} / \mathrm{min}$. The temperature variation during melting and solidification was very small; 82 pct of the latent heat was evolved over $0.04 \mathrm{~K}$ and $50 \mathrm{pct}$ of the latent heat evolved over $0.01 \mathrm{~K}$.

\section{B. Enthalpy Change and Heat Capacity Measurement}

Enthalpy changes were calculated by using Eq. [1] and using $\mathrm{Cu}$ as a calibrant with data from Reference 14. Figure 5(a) shows the enthalpy for pure $\mathrm{Al}$ plotted as a function of temperature. The melting and freezing lines almost coincide. Figure 5(b) shows the heat capacity obtained using the slope of Figure 5(a) for the melting line. The small difference in heat capacity before and after melting is apparent. This would be difficult to detect with a conventional DSC. Another important feature is the narrowness of the latent heat peak. It is not possible to get such a narrow peak

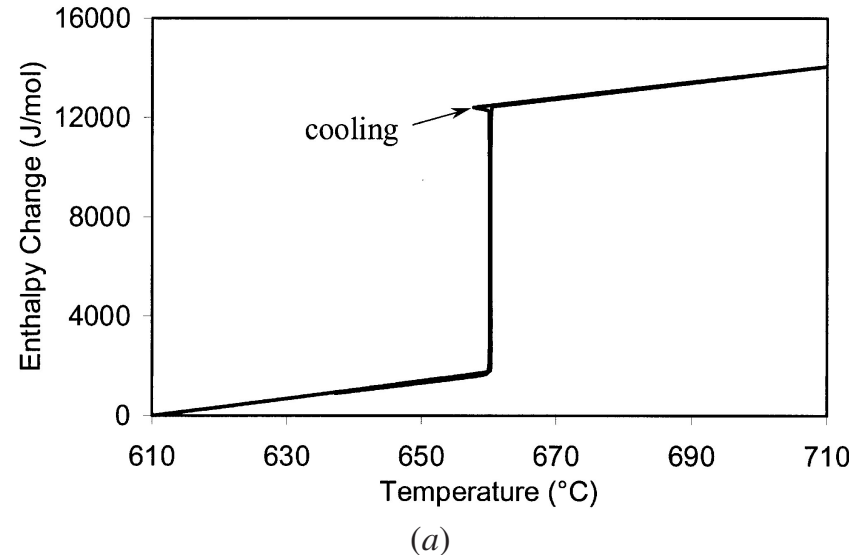

(a)

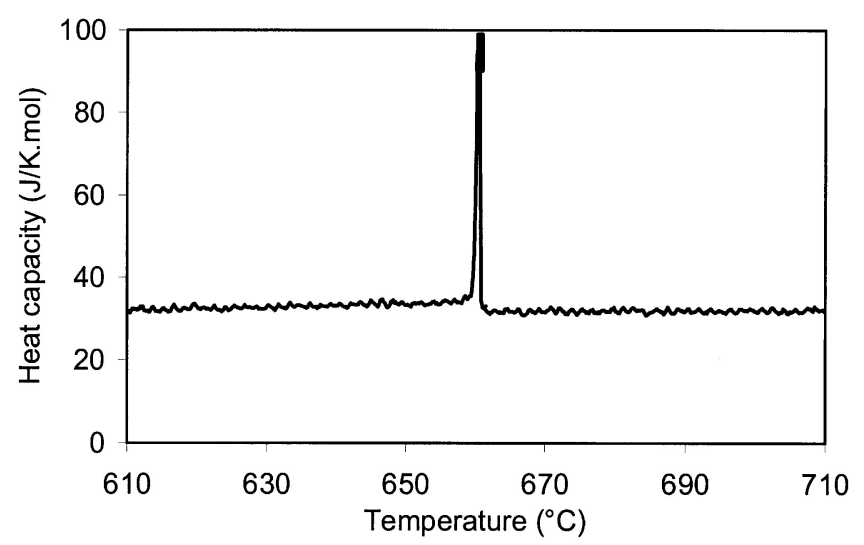

(b)

Fig. 5-Plots for pure Al: (a) enthalpy change vs temperature during melting and freezing and $(b)$ effective heat capacity $v s$ temperature for melting.

with a conventional heat-flux DSC for the reasons discussed earlier. Very good reproducibility was obtained; the average values and standard deviation $(\sigma)$ for seven runs for heat capacity and latent heat are compared with Reference 14 in Table I and show runs carried out with different heat fluxes. Much less than 1 pct variation was obtained with different samples and repeated runs using the same sample.

\section{Sensitivity}

Alloy LM25 (Al - 7.3 wt pct Si, 0.37 wt pct Fe, 0.16 wt pct $\mathrm{Mn}, 0.46$ wt pct $\mathrm{Mg}, 0.07$ wt pct $\mathrm{Cu}$ )

Figures 6(a) and (b) show the enthalpy change and effective heat capacity for LM25 measured using the constant heat-flux mode. The enthalpy line is different for melting and freezing and is consistent with a departure from equilibrium as freezing takes place. The effective heat capacity for melting and for freezing (Figure 6(b)) shows a number of transitions. On freezing, $\mathrm{Al}$ dendrites were formed at about $620{ }^{\circ} \mathrm{C}$ and continued to be deposited until a eutectic ( $\mathrm{Al}+$ $\mathrm{Si})$ came out at about $570{ }^{\circ} \mathrm{C}$; finally, a ternary eutectic ( $\mathrm{Al}$ $+\mathrm{Si}+\beta$ ) was deposited at about $550{ }^{\circ} \mathrm{C}$. On heating, the lowest temperature peak splits into two peaks separated by about $2 \mathrm{~K}$. The additional peak was found to be the result of a solid-state deposit of $\mathrm{Mg}_{2} \mathrm{Si}$. Reactions of the ternary and solid-state deposit were not detected in Reference 15 
Table I. Measured Heat Capacities and Latent Heats for Pure Al Using the Single-Pan Calorimeter

\begin{tabular}{|c|c|c|c|c|c|}
\hline & $\begin{array}{c}C_{p} 600{ }^{\circ} \mathrm{C} \\
(\mathrm{J} / \mathrm{K} / \mathrm{mol})\end{array}$ & $\begin{array}{c}C_{p} 650{ }^{\circ} \mathrm{C} \\
(\mathrm{J} / \mathrm{K} / \mathrm{mol})\end{array}$ & $\begin{array}{l}C_{p} 670{ }^{\circ} \mathrm{C} \\
(\mathrm{J} / \mathrm{K} / \mathrm{mol})\end{array}$ & $\begin{array}{c}L \text { Heating } \\
(\mathrm{J} / \mathrm{mol})\end{array}$ & $\begin{array}{c}L \text { Cooling } \\
(\mathrm{J} / \mathrm{mol})\end{array}$ \\
\hline \multicolumn{6}{|c|}{ Results for seven runs using pure $\mathrm{Al}$} \\
\hline Averaged & 31.5643 & 33.2529 & 31.40 & 10,932 & 10,910 \\
\hline$\sigma$ & \pm 0.1349 & \pm 0.1874 & \pm 0.1460 & \pm 29.31 & \pm 35.36 \\
\hline Ref. 5 & 31.52 & 33.14 & 31.72 & \multicolumn{2}{|c|}{$10,784 \pm 125$} \\
\hline \multicolumn{6}{|c|}{ Results for pure $\mathrm{Al}$ using different heating/cooling rates } \\
\hline $1.5 \mathrm{~K} / \mathrm{min}$ & 31.45 & 33.20 & 31.40 & 11,028 & 10,820 \\
\hline $3.4 \mathrm{~K} / \mathrm{min}$ & 31.56 & 33.25 & 31.40 & 10,932 & 10,910 \\
\hline $4.5 \mathrm{~K} / \mathrm{min}$ & 31.50 & 33.40 & 31.50 & 10,820 & 10,630 \\
\hline
\end{tabular}

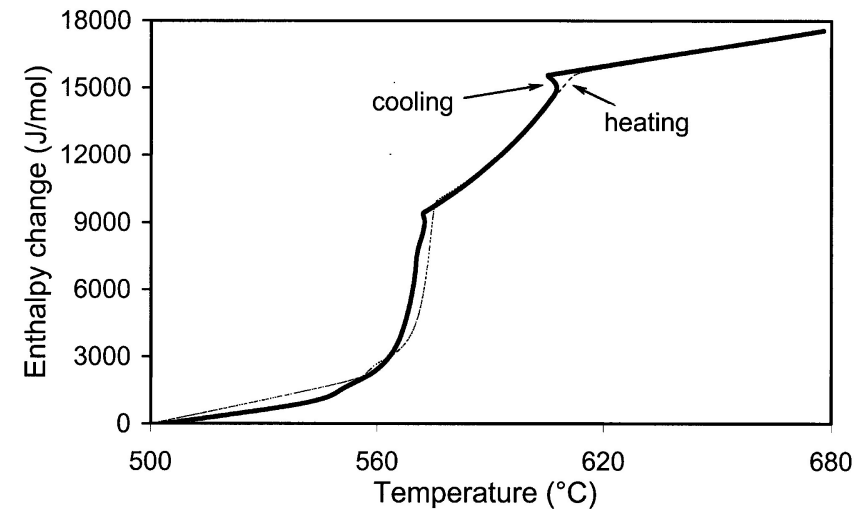

(a)

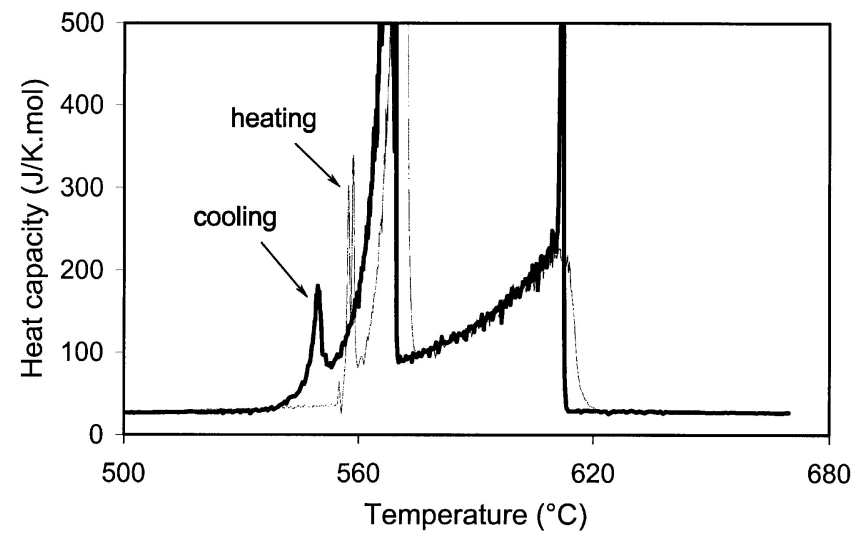

(b)

Fig. 6-Plots for LM25: (a) enthalpy change $v$ s temperature during melting (light line) and freezing (heavy line) and (b) effective heat capacity $v s$ temperature for heating (light line) and cooling (heavy line).

using a conventional heat-flux DSC. The results from electron microprobe analysis and X-ray diffraction confirmed the existence of $\beta$ and $\mathrm{Mg}_{2} \mathrm{Si}$ phases. ${ }^{[16]}$

\section{VOLUME FRACTION AND MICROSEGREGATION DETERMINATION}

\section{A. Alloy Al-4.45 Wt pct Cu}

Figure 7 shows the measured enthalpy for the alloy obtained at four different heat fluxes, 0.067, 0.126, 0.217, and $0.270 \mathrm{~J} / \mathrm{s}$. These correspond to the cooling rates, just

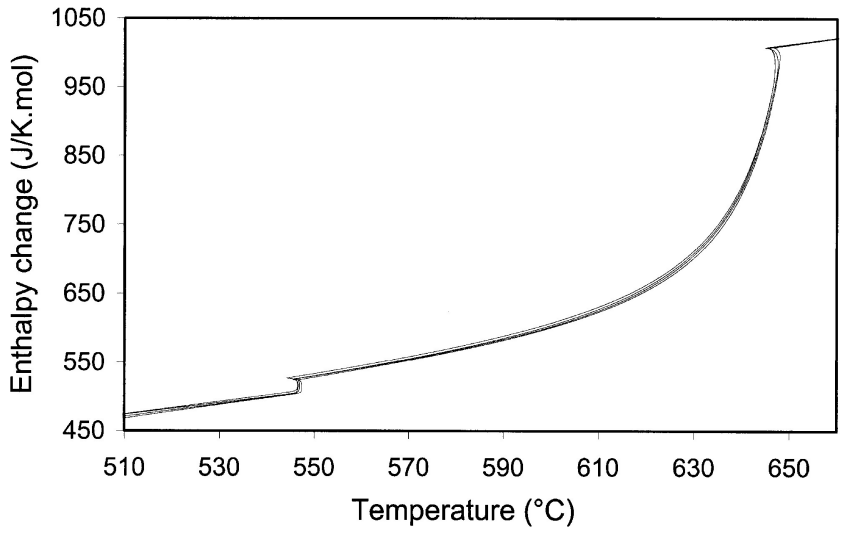

Fig. 7-Measured enthalpies for the Al-Cu4.45 wt pct obtained at four different heat fluxes: $0.067,0.126,0.217$, and $0.270 \mathrm{~J} / \mathrm{s}$.

before freezing, of $1.88,3.99,7.32$, and $9.66 \mathrm{~K} / \mathrm{min}$. The curves show a small amount of supercooling at about 649 ${ }^{\circ} \mathrm{C}$ when $\mathrm{Al}$ nucleates and at about $548{ }^{\circ} \mathrm{C}$ when $\mathrm{CuAl}_{2}$ nucleates to form the eutectic. There is almost no difference between the curves, but the lines remain in the same order during solidification. In this alloy, the limit of solid solubility of $\mathrm{Cu}$ in $\mathrm{Al}$ at the eutectic temperature is 5.7 wt pct $\mathrm{Cu}$; therefore, the eutectic should not be present at equilibrium. The original intention was to use the experimental enthalpy curves to calculate fraction solid and then to compare the experimental fraction solid with theoretical models.

\section{B. Analysis}

It is usual in numerical modeling of alloy solidification to suggest that the enthalpy is given by an expression of the form, e.g., ${ }^{[17]}$

$$
h=C_{p} T+g_{L} L
$$

where $C_{P}, g_{L}$, and $L$ are the heat capacity, fraction liquid, and latent heat. This implies that there is a specific heat term, and a latent heat term that depend on fraction liquid.

This approach would suggest that the fraction liquid could be measured by writing the enthalpy as

$$
\begin{gathered}
h=g_{S} h_{S}+g_{L} h_{L}=\left(1-g_{L}\right) h_{S}+g_{L} h_{L} \\
\text { Solving for } g_{L} \text { gives } g_{L}=\frac{h-h_{S}}{h_{L}-h_{S}}
\end{gathered}
$$




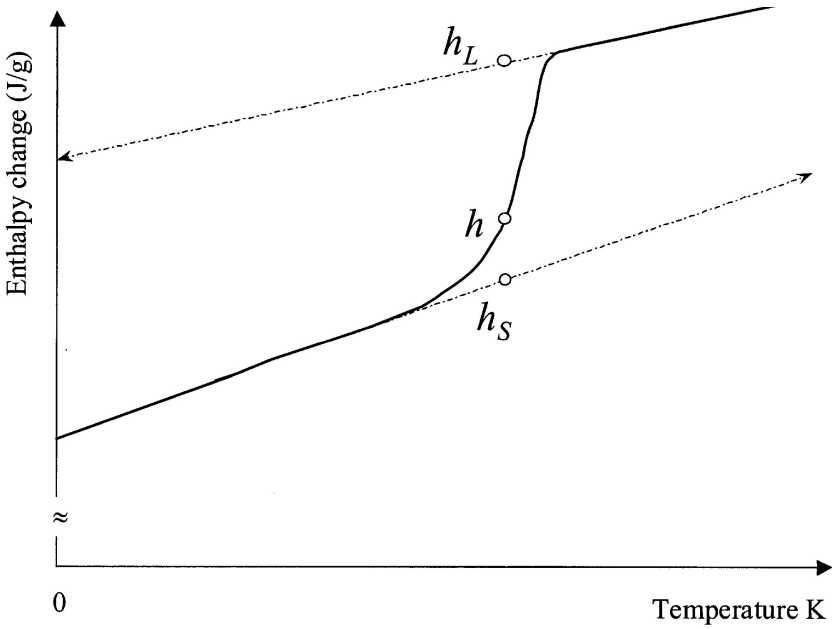

Fig. 8-A schematic plot of enthalpy $v s$ temperature for an alloy.

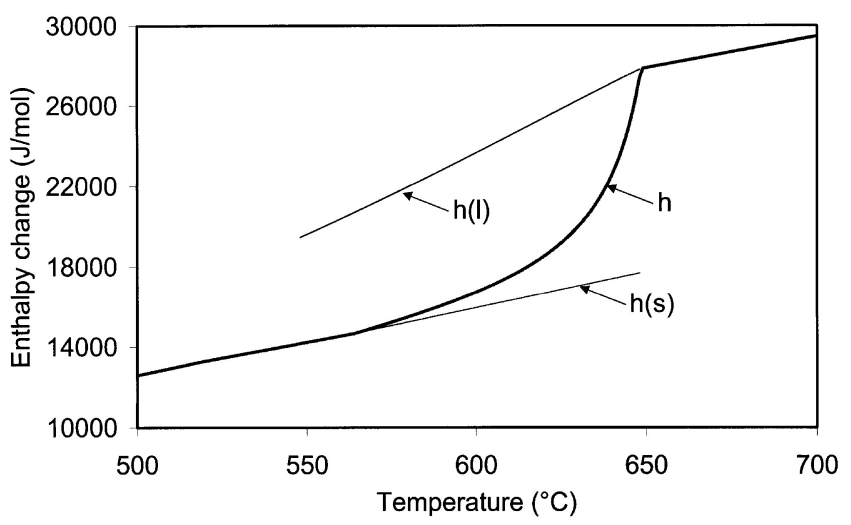

Fig. 9-The enthalpy per mol for liquid $\mathrm{h}(\mathrm{l})$, for solid $\mathrm{h}(\mathrm{s})$, and for the mixture $\mathrm{h}$ calculated at equilibrium using MTDATA.

It is usually suggested that the value could be read from a plot of enthalpy $v s$ temperature by extrapolating the liquid and solid lines, as plotted schematically in Figure 8, and then by taking the ratio (Eq. [3]) from the figure. Figure 8 is slightly more complicated than suggested by Eq. [2], since the heat capacity of the solid and liquid are shown to be different, but this makes little difference to the principle of the calculation.

The problem with this approach is apparent when it is asked: "Does Figure 8 refer to mass, mol, or volume fraction?" The fraction will in general be different for the three different units. The problem is resolved by noting that the liquid and solid enthalpies should not be extrapolated from the completely solid and liquid regions. These represent liquid and solid enthalpies when the composition of the phases remains unchanged. During freezing of an alloy, the liquid composition and the average solid composition change. Figure 9 shows the enthalpy per mol of each phase and that of the mixture calculated at equilibrium using MTDATA. ${ }^{[10]}$ Clearly, when two phases are present the enthalpy changes with composition as well as with temperature. A similar calculation could be carried out for unit mass, which would give the mass fraction. The approximation using the extrapolation in Figure 8 would only apply when the changes in enthalpy with composition are small compared with the difference in enthalpy between pure liquid

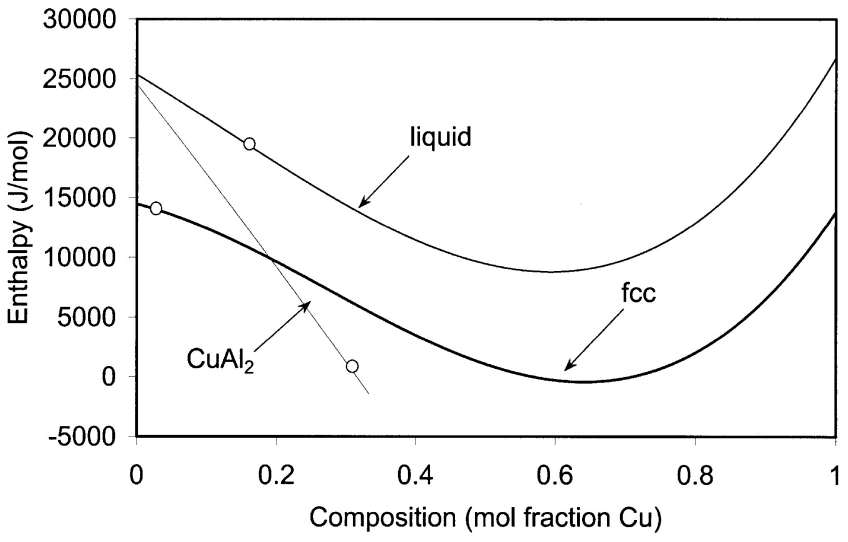

Fig. 10-The enthalpy of liquid $\mathrm{Al}$, solid $\mathrm{Al}$ (fcc), and solid $\mathrm{CuAl}_{2}$ as a function of composition at the eutectic temperature calculated using MTDATA.

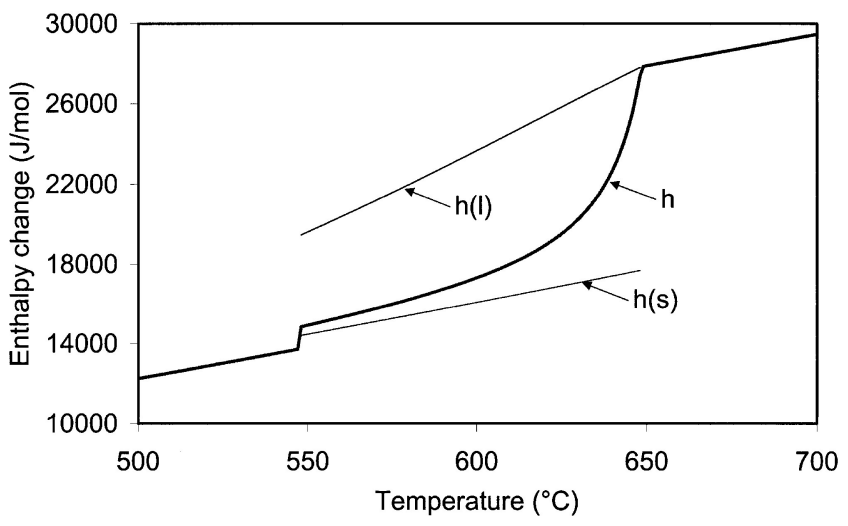

Fig. 11-The enthalpy per mol for liquid $h(1)$, for solid $h(s)$, and for the mixture $h$ assuming the Scheil equation, calculated using MTDATA.

and solid. This is not the case for $\mathrm{Al}-\mathrm{Cu}$, as is shown in Figure 10. This shows the enthalpy of liquid $\mathrm{Al}$ (i.e., an $\mathrm{Al}-$ $\mathrm{Cu}$ liquid solution), solid $\mathrm{Al}$ (i.e., an $\mathrm{Al}-\mathrm{Cu}$ solid solution), and solid $\mathrm{CuAl}_{2}$ at the eutectic temperature calculated using MTDATA. The compositions of the different phases at the eutectic temperature are shown by the points.

Further complications arise. The extreme form of microsegregation occurs when the liquid is mixed, but the solid remains unmixed. The fraction solid can be calculated from the Scheil equation. ${ }^{[18]}$ The enthalpies of one mol of liquid, solid, and the phase mixtures are shown in Figure 11. These were calculated assuming the Scheil equation using MTDATA. ${ }^{[10]}$ The step in the mixture plot arises because of microsegregation. Some liquid remains at the eutectic temperature. The two sets of curves are plotted together in Figure 12. The liquid lines superimpose because the liquid has a uniform composition in both models. The solid lines are different for equilibrium and the Scheil equation. This is because the average solid compositions are different in the two cases. Another point of importance is the completely solid lines are different for the two situations. This is because nonequilibrium solid $\mathrm{CuAl}_{2}$ has a very low enthalpy (Figure 10).

These observations mean that it is not possible to get the fraction liquid directly from enthalpy plots. The line for the enthalpy per mol for the solid depends on the amount of 


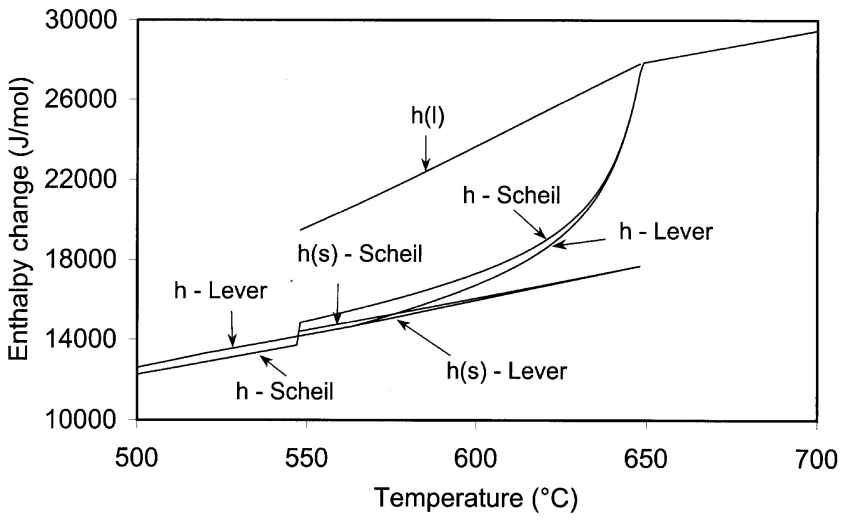

Fig. 12-The two sets of curves (Figs. 9 and 11) plotted together.

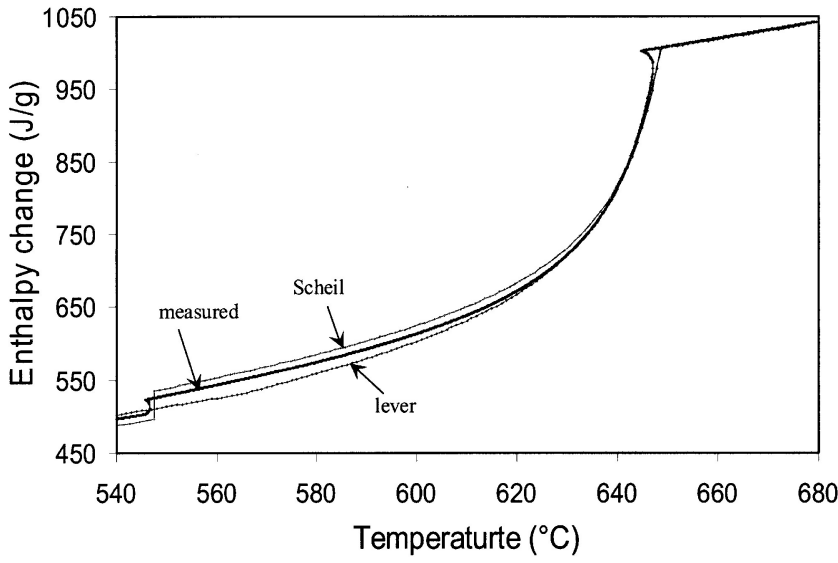

Fig. 13-The measured enthalpy of $\mathrm{Al}-4.45$ wt pct $\mathrm{Cu}$ compared with that calculated assuming the lever rule and the application of the Scheil equation.

microsegregation. If the equilibrium line was used, the amount of liquid calculated would be too high. If the Scheil equation line was used, the fraction calculated would be too small.

It appears to the present authors that the only way to obtain the fraction liquid is to get it indirectly using a model of microsegregation. The composition of different parts of the solid and the liquid can be used to calculate the enthalpy, which can then be compared with the experiment. Figure 13 shows that, as expected, the experimental enthalpy plot lies between that assuming the lever rule and the application of the Scheil equation. Figure 14 shows a comparison between the enthalpy calculated using the microsegregation model, Alloy/M. ${ }^{[9]}$ Alloy/M is a back-diffusion-based model developed from Alloy ${ }^{[19]}$ and is now coupled to the thermophysical data program MTDATA. ${ }^{[10]}$ Alloy and Alloy/M treat microsegregation by treating the diffusion that occurs in the solid phase during solidification. The model considers a slice through an axisymmetric dendrite and treats diffusion in all phases as the slice is cooled. An allowance is made for the dendrite tip temperature, and in present calculations, measured diffusion distances were used. These were measured roughly using a line intercept method. Experiment and theory showed that there was very little difference in enthalpy change for different cooling rates. The amount of eutectic and the eutectic growth temperature fit well (Figure 15). A plot of mol fraction liquid, taken from the microsegregation model, is shown in Figure 16.

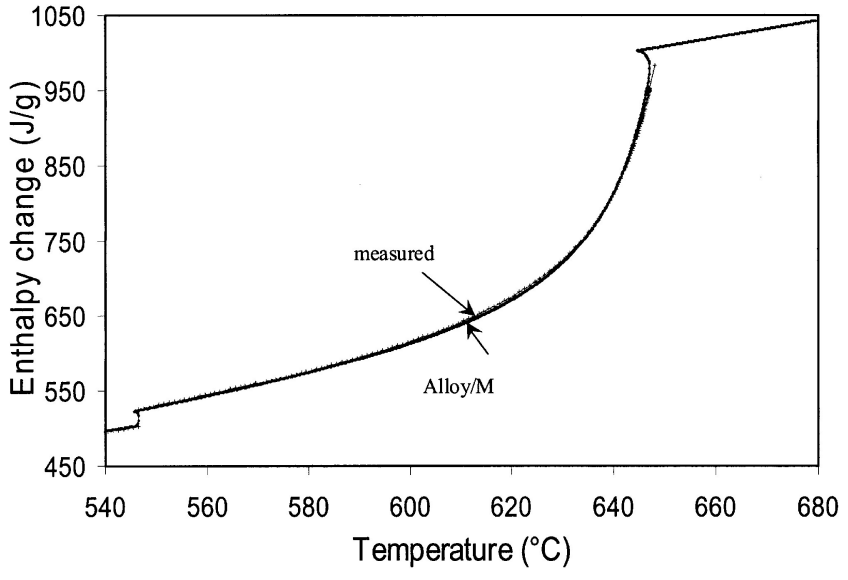

Fig. 14-A comparison between the enthalpy calculated using the microsegregation model "Alloy/M" and measured enthalpy.

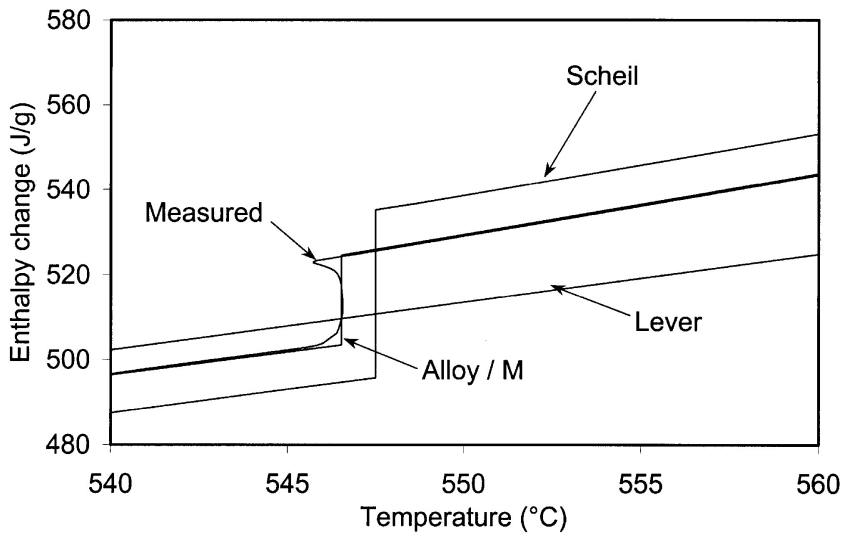

Fig. 15-A comparison between the measured and calculated enthalpy near the eutectic temperature. The figure also shows the plots assuming the lever rule and the Scheil equation.

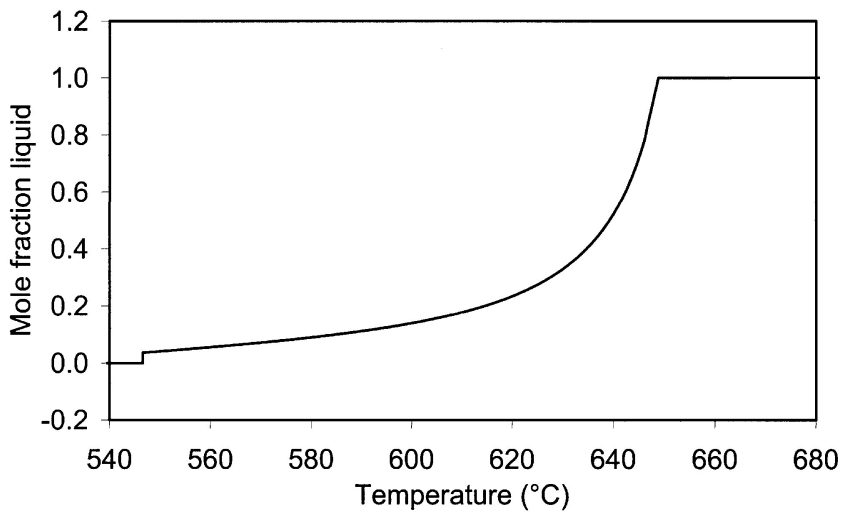

Fig. 16-A plot of mole fraction liquid of Al-4.45 wt pct $\mathrm{Cu}$ calculated using Alloy/M.

In a binary system, the step height in the experimental enthalpy curve can be used to calculate the amount of eutectic. The easiest way to do this would be to experimentally measure the enthalpy change for the eutectic composition and to use this to determine the fraction liquid in an alloy. This is possible because solidification occurs without a change in composition. 
In summary, the present work demonstrates the problem associated with assuming that the enthalpy of an alloy is given by a heat capacity term and a term proportional to fraction liquid times a constant latent heat (Eq. [3]).

\section{CONCLUSIONS}

It is concluded that the present single-pan calorimeter has significant advantages over the conventional heat-flux DSC for measuring enthalpies when phase transformations are taking place or have recently taken place. When used for pure metals, 82 pct of the latent heat appeared over $0.04 \mathrm{~K}$ and reproducibility was better than 1 pct. When used for complex alloys, it was possible to resolve peaks that were less than $1 \mathrm{~K}$ apart.

The work on microsegregation showed that the amount of segregation varied very little with the range of cooling rates obtained in the present research. The enthalpy results could be fitted with a microsegregation model. It was concluded that it was not possible to use the experimental enthalpy data to calculate the fraction solid directly. However, the fraction solid could be indirectly obtained from the microsegregation model, Alloy/M. ${ }^{[9]}$ It is suggested that if accurate enthalpies are required in casting models, it is extremely dangerous to assume that the enthalpy of an alloy is given by a heat capacity term and a term that depends on fraction liquid times a constant latent heat.

\section{REFERENCES}

1. G. Höhne, W. Hemminger, and H.J. Flammersheim: Differential Scanning Calorimetry, Springer, Berlin, 1996, pp. 22-38.
2. B. Wunderlich: Thermal Analysis, Academic Press, New York, NY, 1990, pp. 133-40.

3. N.F. Tsang: Handbook of Differential Thermal Analysis, Chemical Publishing Company, New York, NY, 1966, pp. 91-123.

4. R.F. Speyer: Thermal Analysis of Materials, Marcel Dekker, Inc., New York, NY, 1994.

5. K. O'Reilly and B. Cantor: Proc. R. Soc. London A, 1996, vol. 452, pp. 2141-60.

6. H.B. Dong and J.D. Hunt: High Temperature-High Pressure, 2000, vol. 32, pp. 311-19.

7. H.B. Dong and J.D. Hunt: J. Thermal Anal. Cal., 2001, vol. 64, pp. 167-76.

8. M.J. Richardson: Compendium of Thermophysical Property Measurement Methods, Plenum Press, New York, NY, 1992, pp. 519-45.

9. M.R.M. Shin and J.D. Hunt: Proc. Euromat 2001, Rimini, Italy, doc. 581 .

10. R.H. Davies, A.T. Dinsdale, T.G. Chart, T.I. Barry, and M.H. Rand: High Temp. Sci., 1990, vol. 26, pp. 251-62.

11. D.K. Banerjee, W.J. Boettinger, R.J. Schaefer, and M.E. Williams: Modelling of Casting, Welding and Advanced Solidification Processes VII, TMS, Warrendale, PA, 1995, p. 491.

12. H.B. Dong and J.D. Hunt: J. Thermal Anal. Cal., 2001, vol. 64, pp. 341-50.

13. C.S. Smith: Trans. Am. Inst. Met. Eng., 1940, vol. 137, pp. 236-45.

14. R. Hultgren, P.D. Desai, and D.T. Hawkins: Selected Values of the Thermodynamic Properties of Elements, ASM, Metals Park, OH, 1973, pp. 149-59.

15. P.N. Quested, K.C. Mills, R.F. Brookes, A.P. Day, R. Taylor, and H. Szelagowski: Proc. Int. Conf. on solidification processing, Department of Engineering Materials, University of Sheffield, United Kingdom, 1997, pp. 143-50.

16. H.B. Dong: Ph.D. Thesis, University of Oxford, Oxford, United Kingdom, 2000, pp. 191-220.

17. L. Bäckerud, E. Król, and J. Tammunen: Solidification Characteristics of Aluminium Alloys, Skanaluminium, Oslo, Norway, 1986, vol. 1, pp. 63-73.

18. E. Scheil: Z. Metallkd., 1942, vol. 34, p. 70.

19. J.D. Hunt and R.W. Thomas: Proc. Int. Conf. on Solidification Processing, Department of Engineering Materials, University of Sheffield, United Kingdom, 1997, pp. 143-50. 